\title{
TRANSIENT PHOTO-INDUCED CURRENT MEASUREMENTS IN HIGH RESISTIVITY ZnSe CRYSTALS*
}

\author{
W. Bala, F. Firszt, D. Dul, \\ Institute of Physics, N. Copernicus University, Grudziądzka 5/7, 87-100 Toruń, Poland

\section{Z. TURLO AND J. BORKOWSKI} \\ Laboratory of Astrophysics, Polish Academy of Sciences, Chopina 12/18, 87-100 Toruń, \\ Poland \\ (Received August 8, 1990)
}

\begin{abstract}
Using technique of computerized signal-averaging of photocurrent transient, we have studied the details of deep level states in high resistivity $\mathrm{ZnSe}$ crystals. The time resolved spectra of photocurrent and four-gate PICT spectra are presented.
\end{abstract}

PACS numbers: $72.20 . \mathrm{Jv}, 72.40 .+\mathrm{w}$

Detailed investigations of photoconductivity in II-VI semiconductors have been concentrated mainly on CdS and CdSe single crystals and powders but only few [1-3] on the mechanism of photoconductivity of ZnSe single crystals. The electrical and optical properties of these compounds are often affected by the presence of some dopants or native defects which are easily introduced during the high temperature growth and sample preparation processes. In general in these compounds the photocurrent transients are non-exponential because of a non-linear multi channel recombination mechanisms. The presence of two or more deep traps with nearly equal thermal activation energies could lead to a signal comprised of two or more exponentials, one faster than the other. In order to determine the nature of the traps one has to know whether the transient current is due to electrons or holes.

In this work we have made photo-induced current transient measurements on the high resistivity $\mathrm{ZnSe}$ crystals. The $\mathrm{ZnSe}$ crystals were grown by the high pressure Bridgman method using Koch Light $\mathrm{ZnSe}$ powder as a source material. The

'This work was supported in part by CPBP 01.06. 


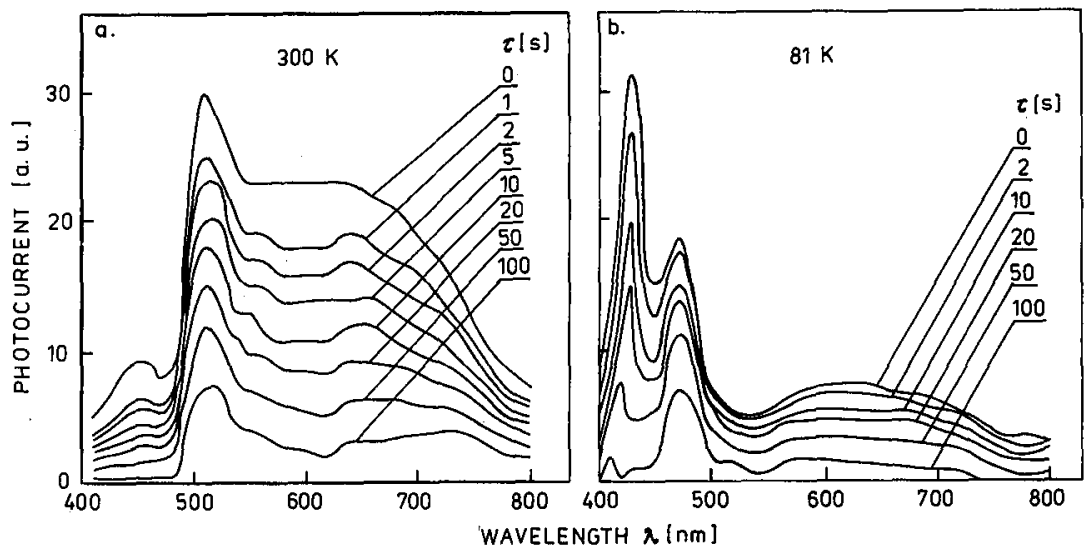

Fig. 1. Photo-induced current for ZnSe crystal at room temperature (a) and at $81 \mathrm{~K}$ (b) measured at different delay times after excitation light pulse.

crystal was cut onto $1 \mathrm{~mm}$ thick plates and annealed in liquid $\mathrm{Zn}$ containing $10 \%$ of $\mathrm{Al}$ at a temperature of $1220 \mathrm{~K}$ during 70 hours. After mechanical polishing and chemical etching indium contacts were alloyed to $\mathrm{ZnSe}$ samples. The $\mathrm{ZnSe}$ crystal was attached to the cold finger of a cryostat and the temperature could be set with a precision of $0.1 \mathrm{~K}$ and maintained within $0.2 \mathrm{~K}$ of the set point for periods as long as several minutes. A constant voltage was applied across the sample, and the current was measured by monitoring the voltage across a resistor in series with the sample. Light from the halogen $50 \mathrm{~W}$ lamp through SPM-2 (Zeiss) monochromator was focused on the sample. We have used electromechanical shutter with the off time less than $1 \mathrm{~ms}$. We use a digital approach which offers the possibility of recording and storing the entire decay PICT signals at various excitation conditions. The data can be sampled at 20000 points with 16-bit accuracy. The stored data were analyzed using the so-called four-gate technique [4-9]. In Fig. 1. we present the results of measurements of photo-current decay after excitation of ZnSe crystals with light of different wavelengths at RT and $81 \mathrm{~K}$. The spectral photoresponse for photoconductivity at $81 \mathrm{~K}$ exhibits three maxima at about 430 , 465 and $620 \mathrm{~nm}$, which correspond to the band to band, shallow and deep levels transitions, respectively. As the delay time increases the $430 \mathrm{~nm}$ peak shifts towards shorter wavelengths, while the 465 and $620 \mathrm{~nm}$ maxima remain unchanged. The time resolved spectra (TRS) have been investigated by PICT spectroscopy in high resistivity $\mathrm{ZnSe}$ for the first time. The obtained PICT data seem to require three or four separate exponential decays to fit the experimental results. With the use an extrinsic excitation a photoconductivity is excited by electron transitions from the acceptor level to the conduction band. As a result holes remain trapped in the acceptor level because their thermal emission into the valence band is not possible at low temperature. The relaxation process is simply determined by the capture of photoelectrons by the traps, followed by radiative recombination with 
the holes in the acceptor level [9].


Fig. 2. Four-gate PICT spectrum for $\mathrm{ZnSe}$ crystal for the emission time $\tau_{\mathrm{m}}=15 \mathrm{~s}$, $t_{2} / t_{1}=1.5(\mathrm{a})$, and $\tau_{\mathrm{m}}=23 \mathrm{~s}, t_{2} / t_{1}=1.5(\mathrm{~b})$.

Fig. 2a and $2 \mathrm{~b}$ show a typical PICT spectra generated by four-gate signal processing $[4,6,9]$. Four well-separated peaks are revealed indicating the presence of four trapping levels. From a series of spectra corresponding to different values of $\tau_{\mathrm{m}}$ an Arrhenius plot can be constructed for each maximum. The activation energies of carrier emission $E_{\mathrm{T}}$ of these traps were estimated as: $0.20 \pm 0.02 \mathrm{eV}$, $0.26 \pm 0.02 \mathrm{eV}, 0.34 \pm 0.02 \mathrm{eV}$ and $0.38 \pm 0.02 \mathrm{eV}$. The electron traps with the activation energies $0.38 \mathrm{eV}$ are minority defects. We assume, according to the work of IIeurtel et al. [10], that this level is connected with $\mathrm{Zn}$ which has to be stabilized in same way in the lattice or by interaction with another defect. All DLTS spectra for low resistivity $\mathrm{ZnSe}$ crystals which were annealed in molten $\mathrm{Zn}$ are often dominated by the single peak. This electron trap has the thermal activation energy of $0.34 \mathrm{eV}[11]$.

\section{References}

[1] R.H. Bube, E.L. Lind, Phys. Rev. 110, 1040 (1958).

[2] S. Adachi, Y. Machi, Jpn. J. Appl. Phys. 15, 1513 (1976).

[3] R.H. Bube, Photoconductivity of Solids, Wiley, New York 1960.

[4] J.C. Balland, J.P. Zielinger, C. Noguet, M. Tapiero, J. Phys. D, Appl. Phys. 19, 57 (1986).

[5] J.C. Balland, J.P. Zielinger, M. Tapiero, J.G. Gross, C. Noguet, J. Phys. D, Appl. Phys. 19, 71 (1986).

[6] R.E. Kremer, M.C. Arikan, J.C. Abele, J.S. Blakemore, J. Appl. Phys. 62, 2424 (1987).

[7] J.C. Abele, R.E. Kremer, J.S. Blakemore, J. Appl. Phys. 62, 2432 (1987). 
[8] J.P. Zielinger, B. Pohoryles, J.C. Balland, J.G. Gross, A. Coret, J. Appl. Phys. 57, 293 (1985).

[9] A. Serpi, M. Tapiero, J.P. Zielinger, Phys. Status Solidi A 93, 241 (1986).

[10] A. Heurtel, R. Legros, Y. Marfaing, R. Triboulet, Materials Science Forum 10-12, 833 (1986).

[11] W. Bala, Acta Phys. Pol. A69, 783 (1986). 